\title{
Ascertainment of Silent Myocardial Infarction in Patients Undergoing Percutaneous Coronary Intervention (from the GLOBAL LEADERS Trial)
}

\author{
Chun Chin Chang, MD ${ }^{\mathrm{a}, \mathrm{b}}$, Ernest Spitzer, MD ${ }^{\mathrm{a}, \mathrm{c}}$, Ply Chichareon, MD ${ }^{\mathrm{d}}$, Kuniaki Takahashi, MD ${ }^{\mathrm{d}}$, \\ Rodrigo Modolo, $\mathrm{MD}^{\mathrm{d}}$, Norihiro Kogame, MD ${ }^{\mathrm{d}}$, Mariusz Tomaniak, MD ${ }^{\mathrm{a}, \mathrm{e}}$, Hidenori Komiyama, $\mathrm{MD}^{\mathrm{d}}$, \\ Sing-Chien Yap, MD, PhD ${ }^{\mathrm{a}}$, Stephen P. Hoole, $\mathrm{MD}^{\mathrm{f}}$, Tommaso Gori, $\mathrm{MD}^{\mathrm{g}}$, Azfar Zaman, $\mathrm{MD}^{\mathrm{h}}$, \\ Bernhard Frey, MD ${ }^{\mathrm{i}}$, Rui Cruz Ferreira, MD $\mathrm{M}^{\mathrm{j}}$, Olivier F. Bertrand, MD, PhD ${ }^{\mathrm{k}}$, Tian Hai Koh, MD', \\ Amanda Sousa, $\mathrm{MD}^{\mathrm{m}}$, Aris Moschovitis, $\mathrm{MD}^{\mathrm{n}}$, Robert-Jan van Geuns, $\mathrm{MD}, \mathrm{PhD}^{\mathrm{a}, \mathrm{o}}$, \\ Philippe Gabriel Steg, MD ${ }^{\mathrm{p}}$, Christian Hamm, MD ${ }^{\mathrm{q}, \mathrm{r}}$, Peter Jüni, DM ${ }^{\mathrm{s}, \mathrm{t}}$, Pascal Vranckx, MD, PhD ${ }^{\mathrm{u}}$,

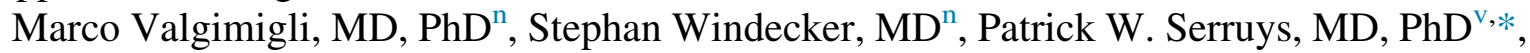 \\ Osama Soliman, $\mathrm{MD}, \mathrm{PhD}^{\mathrm{a}, \mathrm{c}}$, and Yoshinobu Onuma, $\mathrm{MD}, \mathrm{PhD}^{\mathrm{a}, \mathrm{c}}$
}

\begin{abstract}
Q-wave myocardial infarction (QWMI) comprises 2 entities. First, a clinically evident MI, which can occur spontaneously or be related to a coronary procedure. Second, silent MI which is incidentally detected on serial electrocardiographic (ECG) assessment. The prevalence of silent MI after percutaneous coronary intervention (PCI) in the drug-eluting stent era has not been fully investigated. The GLOBAL LEADERS is an all-comers multicenter trial which randomized 15,991 patients who underwent PCI to 2 antiplatelet treatment strategies. The primary end point was a composite of all-cause death or nonfatal new QWMI at 2-years follow-up. ECGs were collected at discharge, 3-month and 2-year visits, and analyzed by an independent ECG core laboratory following the Minnesota code. All new QWMI were further reviewed by a blinded independent cardiologist to identify a potential clinical correlate by reviewing clinical information. Of 15,968 participants, ECG information was complete in $14,829(92.9 \%)$ at 2 years. A new QWMI was confirmed in $186(1.16 \%)$ patients. Transient new Q-waves were observed in $28.5 \%$ (53 of 186) of them during the follow-up. The majority of new QWMI (78\%, 146 of 186) were classified as silent MI due to the absence of a clinical correlate. Silent MI accounted for $22.1 \%$ (146 of 660) of all MI events. The prevalence of silent MI did not differ significantly between treatment strategies (experimental vs reference: $0.88 \%$ vs $0.98 \%, p=0.5027$ ). In conclusion, we document the prevalence of silent $\mathrm{MI}$ in an all-comers population undergoing PCI in this large-scale randomized trial. (c) 2019 Elsevier Inc. All rights reserved. (Am J Cardiol 2019;124:1833-1840)
\end{abstract}

Silent or unrecognized myocardial infarction (MI) was identified as a clinical entity several decades before the era of percutaneous coronary intervention (PCI). ${ }^{1}$ Currently, silent $\mathrm{MI}$ is defined by the appearance of new pathological

\footnotetext{
${ }^{a}$ Department of Cardiology, Thoraxcenter, Erasmus Medical Center, Rotterdam, the Netherlands; ${ }^{\mathrm{b}}$ Division of Cardiology, Department of Internal Medicine, Taipei Veterans General Hospital, Institute of Clinical Medicine, National Yang Ming University, Taipei, Taiwan; ${ }^{\mathrm{c} C a r d i a l y s i s ~ B . V ., ~ R o t t e r-~}$ dam, the Netherlands; ${ }^{\mathrm{d}}$ Academic Medical Center, University of Amsterdam, Amsterdam, the Netherlands; ' First Department of Cardiology, Medical University of Warsaw, Warsaw, Poland; ${ }^{\mathrm{f}}$ Department of Interventional Cardiology, Royal Papworth Hospital, Cambridge, United Kingdom; ${ }^{\mathrm{g}}$ Zentrum für Kardiologie, Kardiologie I, University Medical Center, and DZHK Standort Rhein-Main, Mainz, Germany; ${ }^{\mathrm{h}}$ Freeman Hospital, Newcastle upon Tyne NHS Hospitals Trust and Institute of Cellular Medicine, Newcastle University, United Kingdom; 'Department of Internal Medicine II, Medical University Vienna, Vienna, Austria; ${ }^{\mathrm{j}}$ Cardiology Department, Santa Marta Hospital, Lisbon, Portugal; ${ }^{k}$ Quebec Heart-Lung Institute, Laval University, Quebec City, Quebec, Canada; ${ }^{1}$ National Heart Center Singapore, Singapore; ${ }^{\mathrm{m}}$ Instituto Dante Pazzanese de Cardiologia, Sao Paulo, Brazil; ${ }^{\mathrm{n}}$ Department of Cardiology, University of Bern, Inselspital, Bern, Switzerland; ${ }^{\circ}$ Department of Cardiology, Radboud UMC, Nijmegen, the Netherlands; ${ }^{\mathrm{P} D e ́ p a r t e m e n t ~ d e ~ C a r d i o l o g i e, ~ H o ̂ p i t a l ~ B i c h a t, ~ H o ̂ p i t a u x ~}$
}

Q-waves on an electrocardiogram (ECG) or cardiac imaging evidence of infarction without an identifiable clinical correlate (e.g., acute coronary syndrome or coronary revascularization) during follow-up. ${ }^{2}$ The frequency of silent MI

Universitaires Paris Nord Val de Seine, Assistance Publique - Hôpitaux de Paris, Paris, France; ${ }^{\mathrm{q}}$ Kerckhoff Clinic, Bad Nauheim, Germany; ${ }^{\mathrm{r}} \mathrm{DZHK}$ (German Centre for Cardiovascular Research), Frankfurt, Germany; ${ }^{\mathrm{s}} \mathrm{Ap}-$ plied Health Research Centre, Li Ka Shing Knowledge Institute of St Michael's Hospital, Toronto, Ontario, Canada; 'Department of Medicine, Institute of Health Policy, Management and Evaluation University of Toronto, Toronto, Ontario, Canada; "Jessa Ziekenhuis, Faculty of Medicine and Life Sciences at the Hasselt University, Hasselt, Belgium; and ${ }^{\mathrm{V} N H L I}$, Imperial College London, London, United Kingdom. Manuscript received May 6, 2019; revised manuscript received and accepted August 30, 2019.

Funding: This study was sponsored by the European Cardiovascular Research Institute (ECRI, Rotterdam, the Netherlands) that received funding from one device (Biosensors International Ltd, Europe) and two drug manufacturers (Astra Zeneca, Cambridge United Kingdom; The Medicines Company, Parsippany; United States of America).

See page 1839 for disclosure information.

*Corresponding author: Tel: +31-10-4635260; fax: +31-10-4369154.

E-mail address: patrick.w.j.c.serruys@gmail.com (P.W. Serruys). 
has been reported as comprising around $1 / 3$ of all MIs from several large cohort studies. ${ }^{3,4}$ A mounting body of evidence has demonstrated that silent MI is associated with an increased risk of all-cause death, heart failure, and reinfarction. ${ }^{5-7}$ Despite its prognostic impact, silent MI is rarely addressed in contemporary coronary intervention trials. The prevalence of silent MI after PCI with drug-eluting stents has not yet been fully investigated. Timing of surveillance, analysis methodology, and appropriate use of this end point are current research interests. In this context, we report on the assessment of new Q-wave MI (QWMI) in the GLOBAL LEADERS trial and summarize findings with respect to silent and clinically evident events.

\section{Methods}

The details of the GLOBAL LEADERS trial have been reported previously. ${ }^{8,9}$ In the investigator-initiated, multicenter, prospective randomized GLOBAL LEADERS trial, 15,991 patients who underwent PCI with Biolimus A9 eluting stents were randomly assigned to 2 antiplatelet treatment strategies. In the experimental treatment strategy, patients received aspirin 75 to $100 \mathrm{mg}$ once daily in combination with ticagrelor $90 \mathrm{mg}$ twice daily for 1 month; followed by ticagrelor $90 \mathrm{mg}$ twice daily monotherapy for 23 months (irrespective of the clinical presentation). In the reference treatment strategy, patients received aspirin 75 to $100 \mathrm{mg}$ daily in combination with either clopidogrel $75 \mathrm{mg}$ once daily in patients with stable coronary artery disease or ticagrelor $90 \mathrm{mg}$ twice daily in patients with acute coronary syndromes for 1 year; followed by aspirin 75 to $100 \mathrm{mg}$ once daily monotherapy between 1 and 2 years. The primary end point was a composite of all-cause death or nonfatal new QWMI at 2 years of follow-up.

Resting 12-lead ECGs at hospital discharge, 3-months follow-up, and the 2-year end-of-trial visit and any available intercurrent ECGs, related to suspected ischemic events, were inspected for quality and technical errors and analyzed by an independent ECG-core laboratory (Cardialysis, Rotterdam, The Netherlands). The ECG acquisition guidelines are provided in the appendix. All of the missing ECGs or noninterpretable ECGs were queried, and the investigator were requested to forward a new recording.

Serial comparison of sequential ECGs was performed to identify patients with new appearance of $\mathrm{Q}$ waves (major Q-QS wave abnormalities 1-1-1 to 1-2-7 according to the Minnesota Code 2009). ${ }^{10}$ All core laboratory detected new QWMIs were reviewed by a blinded independent medical reviewer (BIMR). Where new $\mathrm{Q}$ waves, with respect to the immediately preceding ECGs (first reference ECG was at discharge), were identified, the BIMR confirmed or rejected the event as a new QWMI and if confirmed also assigned a date, based on review of the reported clinical events to the new QWMI. Where no clinical correlate was identified, the date of the new QWMI was arbitrarily assigned to the date of the qualifying ECG. When the BIMR disagreed with the new $\mathrm{Q}$ waves, he requested a reassessment by the core lab. The initial or subsequent assessment by the core lab was the final decision. When the other co-primary end point (all-cause death) occurred or when there was no clinical event up to 2 years occurred and there was no 2-year ECG it was assumed that no new QWMI had occurred. When a new QWMI followed by death in a short time ( $<28$ days), it was considered to be fatal and did not count for the end point of new QWMI.

The BIMR was also responsible for reviewing the sitereported new QWMI that had not been reported by the core lab. This review was performed after the 2-year ECG had been received or was confirmed to be permanently missing. When the BIMR identified a likely new QWMI between discharge and 2-years follow-up, the core lab was requested to reassess the ECGs. The ECG-core lab also identified new occurrences of left bundle branch block (LBBB) on serial ECGs. When a new LBBB was identified, the BIMR determined whether a likely ischemic event (prolonged ischemic chest pain, significant rise in cardiac biomarkers or imaging evidence of loss of viable myocardium) occurred according to the electronic clinical record form when necessary with additional source documents. A new occurrence of LBBB counted as a new QWMI equivalent only when a qualifying ischemic event was identified. The new QWMI equivalent was assigned to the date of the qualifying ischemic event. ECG analysts and the BIMR were unaware of the study-group assignments. With respect to clinically evident MI (periprocedural or spontaneous), it was site-reported according to the Third Universal Myocardial Infarction definition as study specific MI criteria. ${ }^{11}$

Categorical variables were presented as percentages and numbers and compared with the use of the Chi-square test or Fisher's exact test. Continuous variables were compared with Student's $t$ test or analysis of variance test. KaplanMeier method was used to estimate the cumulative rates of time to event end points and log-rank test was performed to examine the differences between groups. A 2-sided $\mathrm{p}$ value of $<0.05$ was considered to indicate statistical significance. Data were analyzed using SPSS software (version 25, SPSS, Chicago, Illinois).

\section{Results}

The GLOBAL LEADERS trial enrolled 15,991 patients, of whom 23 subsequently withdrew consent and requested deletion of their data from the database, leaving 15,968 patients for the final analysis. Vital status was obtained in all but 8 patients $(99.95 \%)$. The study flow chart is shown in Figure 1. At 2-year follow-up, the ECG information was complete in $93.3 \%(7,446$ of 7,980$)$ patients in the experimental group and $92.4 \%(7,383$ of 7,985$)$ in the reference group.

During the 2-year follow-up, new Q-waves on the ECG were reported by investigators in 70 patients. Of those investigator-reported new QWMI, 24.3\% (17 of 70) were further confirmed by the BIMR and the review of the core lab. Overall, new QWMI was detected or confirmed by the core lab in 183 patients (3-month, $\mathrm{n}=94$; 2-year, $\mathrm{n}=69$; intercurrent, $\mathrm{n}=20$ ) and new LBBB in additional 3 patients was considered equivalent to a new QWMI by the BIMR. The prevalence of new QWMI was $1.16 \%$ (186 of 15,968).

Of 186 new QWMI, 40 (21.5\%) were adjudicated as clinically correlated QWMI by the BIMR, whereas 146 (78.5\%) were nonclinically correlated. Comparison of baseline characteristics between clinically and nonclinically 


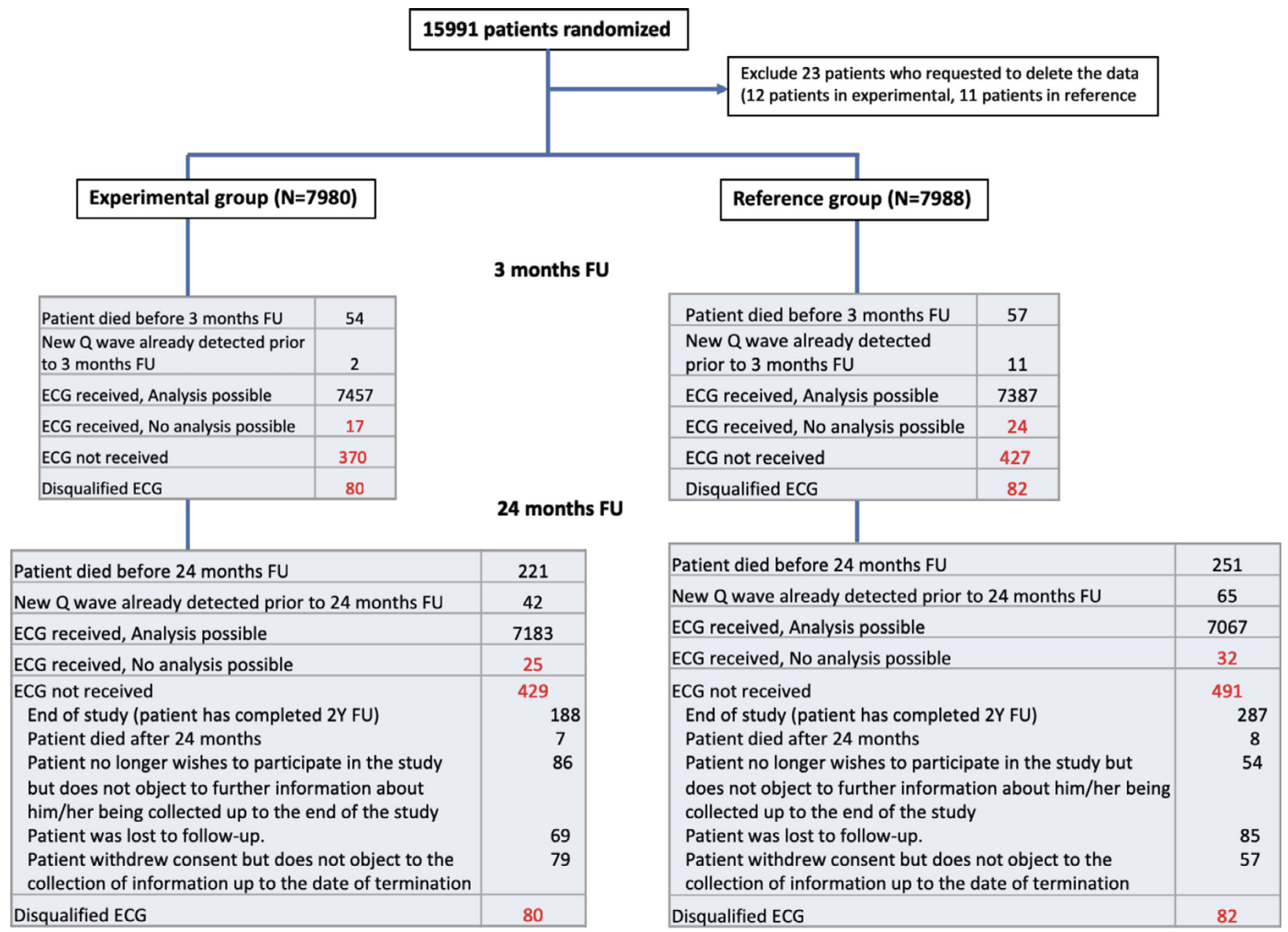

Figure 1. Study flow chart.

correlated new QWMI is shown in Table 1. Patients with clinically correlated new QWMI more frequently had peripheral vascular disease (17.5\% [7 of 40] vs $4.9 \%$ [7 of $144] ; \mathrm{p}=0.014)$ and previous MI $(55.0 \%$ [22 of 40] vs $30.6 \%$ [44 of 144]; $\mathrm{p}=0.005$ ) compared with those with nonclinically correlated new QWMI.

Of the 498 patients with site-reported MI during the 2-year follow-up, 32 patients also had a core lab identified new QWMI (24 clinically correlated and 8 nonclinically correlated) (Figure 2). When the date of the event between site-reported MI and BIMR identified new QWMI was more than 28 days, it was considered as 2 independent events. According to the date of events, 24 patients with BIMR identified clinically correlated new QWMI had 27 MI events, whereas 8 patients with nonclinically correlated new QWMI had 13 MI events. In total, 652 patients had 660 MI events. Patients who had site-reported MI or clinically correlated new QWMI were classified as "clinical MI" group $(\mathrm{n}=506)$, whereas those who had nonclinically correlated new QWMI were classified as "silent MI" group $(\mathrm{n}=146)$. Baseline characteristics stratified by MI status are shown in Table 2. The silent MI group was older, less likely to be a smoker and more frequently presented with stable coronary artery disease than the clinical MI group, whereas the frequency of co-morbidities did not significantly differ between 2 groups.

At 2-year follow-up, clinical MI had occurred in 250 (3.1\%) patients in the experimental group and $256(3.2 \%)$ in the reference group. Silent MI was identified in 69 $(0.9 \%)$ patients in the experimental group and $77(1.0 \%)$ in the reference group. The cumulative incidence of clinical and silent MI did not differ significantly between groups (Figures 3 and 4).

\section{Discussion}

In the GLOBAL LEADERS trial, we documented the prevalence of new QWMI including silent MI in an allcomers population with coronary artery disease undergoing PCI, by serial ECG assessment with central adjudication. Silent MI accounted for $78.5 \%$ of new QWMI and $22.1 \%$ of total MI events. Patients with silent MI had similar baseline characteristics as those with clinical MI. At 2-year follow-up, the experimental antiplatelet treatment did not result in significant differences in rates of clinical MI and silent MI compared with the reference treatment.

Currently, the majority of data available on the incidence or prevalence of silent MI originates from previous large 
Table 1

Blinded independent medical reviewer-identified clinically correlated versus nonclinically correlated new Q-wave myocardial infarction

\begin{tabular}{|c|c|c|c|}
\hline & $\begin{array}{c}\text { Clinically correlated } \\
\text { new QWMI } \\
(\mathrm{n}=40)\end{array}$ & $\begin{array}{c}\text { Nonclinically correlated } \\
\text { new QWMI } \\
(\mathrm{n}=146)\end{array}$ & $\mathrm{p}$ Value \\
\hline Age (years) & $65.4 \pm 10.6$ & $67.0 \pm 10.6$ & 0.414 \\
\hline Male & $34 / 40(85.0 \%)$ & $105 / 146(71.9 \%)$ & \multirow[t]{2}{*}{0.104} \\
\hline Female & $6 / 40(15.0 \%)$ & $41 / 146(28.1 \%)$ & \\
\hline Body mass index $\left(\mathrm{kg} / \mathrm{m}^{2}\right)$ & $27.6 \pm 4.8$ & $28.3 \% \pm 4.2$ & 0.322 \\
\hline Insulin-dependent diabetes mellitus & $4 / 40(10.0 \%)$ & $17 / 146(11.6 \%)$ & 1.000 \\
\hline Hypertension & $30 / 40(75.0 \%)$ & $108 / 145(74.5 \%)$ & 1.000 \\
\hline Hypercholesterolemia & $29 / 39(74.4 \%)$ & $91 / 141(64.5 \%)$ & 0.337 \\
\hline Current smoker & $11 / 40(27.5 \%)$ & $28 / 146(19.2 \%)$ & 0.276 \\
\hline Peripheral vascular disease & $7 / 40(17.5 \%)$ & $7 / 144(4.9 \%)$ & 0.014 \\
\hline Chronic obstructive pulmonary disease & $5 / 40(12.5 \%)$ & $8 / 145(5.5 \%)$ & 0.159 \\
\hline Previous coronary artery bypass grafting & $6 / 40(15.0 \%)$ & $17 / 1462(11.6 \%)$ & 0.590 \\
\hline \multicolumn{4}{|l|}{ Clinical presentation } \\
\hline Stable coronary artery disease & $26 / 40(65.0 \%)$ & $86 / 146(58.9 \%)$ & \multirow[t]{2}{*}{0.585} \\
\hline Acute coronary syndrome & $14 / 40(35.0 \%)$ & $60 / 146(41.1 \%)$ & \\
\hline \multicolumn{4}{|l|}{ Antiplatelet treatment } \\
\hline Experimental strategy & $14 / 40(35.0 \%)$ & $69 / 146(47.3 \%)$ & \multirow[t]{2}{*}{0.209} \\
\hline Reference strategy & $26 / 40(65.0 \%)$ & $77 / 146(52.7 \%)$ & \\
\hline
\end{tabular}

Data are shown as mean \pm standard deviation or number of patients $(\%)$.

* Defined as an estimated glomerular filtration rate of creatinine clearance of $<60 \mathrm{ml} / \mathrm{min}$ per $1.73 \mathrm{~m}^{2}$ based on the Modification of Diet in Renal Disease formula. QWMI = Q-wave myocardial infarction.

cohorts of patients without PCI. ${ }^{4}$ In our study, the prevalence of silent MI $(0.91 \%)$ was in the range of previously reported data $(0.37 \%$ to $3.37 \%){ }^{4}$ The Bypass Angioplasty Revascularization Investigation 2 Diabetes study ${ }^{12}$ in 2,368 diabetic patients with coronary artery disease assigned to either prompt revascularization or medical therapy alone showed that nonfatal silent MI occurred in $0.97 \%$ (23 of 2,368 ) of patients and accounted for $8 \%$ of all MI during an average of 5.3-year follow-up. ${ }^{13}$ Recently, Zhang et al showed that silent MI occurred in 3.3\% of participants who were free of cardiovascular disease at baseline in the Atherosclerosis Risk In Communities study during a median

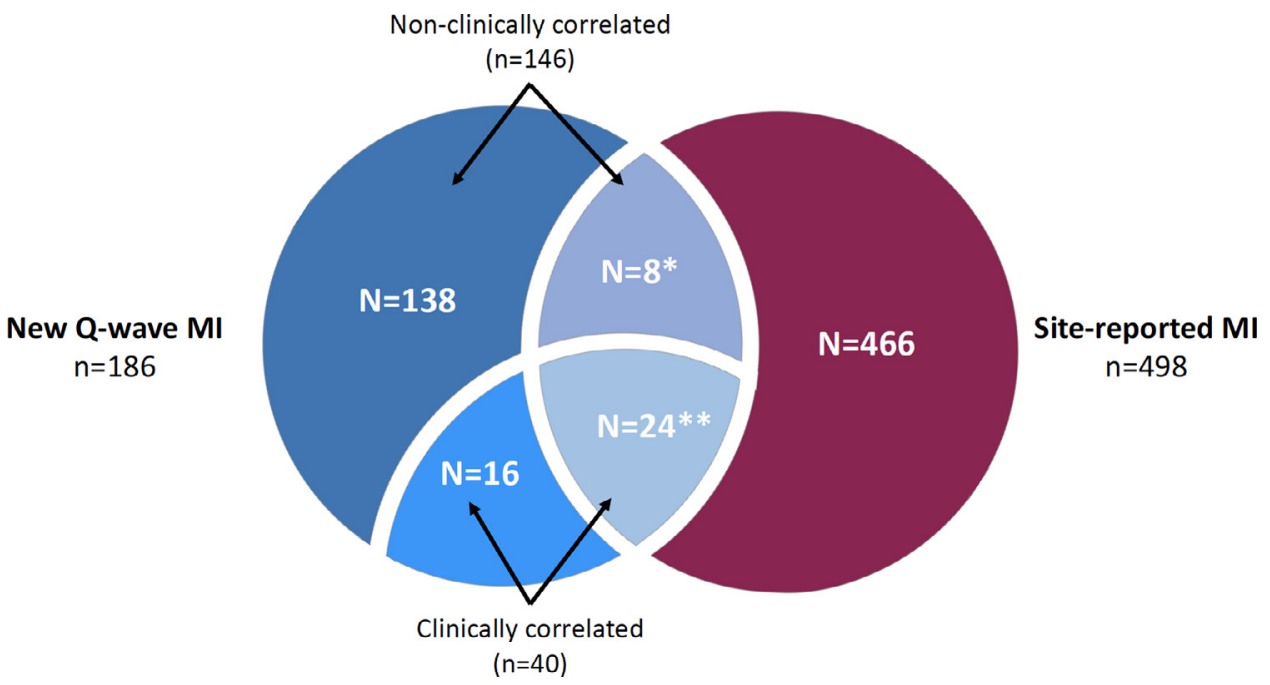

Figure 2. Classification of site-reported and blinded independent medical reviewer-identified new Q-wave myocardial infarction. Thirty-two (24 clinically correlated and 8 nonclinically correlated) patients had both blinded independent medical reviewer (BIMR)-identified nonfatal new Q-wave myocardial infarction and site-reported myocardial infarction. When the date of event between 2 types of MI was more than 28 days, it was considered as 2 independent events. * 8 patients had 13 MI events; ** 24 patients had 27 MI events, MI = myocardial infarction. 
Table 2

Baseline characteristics of patients stratified by myocardial infarction status

\begin{tabular}{|c|c|c|c|c|}
\hline & $\begin{array}{l}\text { No myocardial } \\
\text { infarction } \\
(\mathrm{n}=15,316)\end{array}$ & $\begin{array}{l}\text { Silent myocardial } \\
\text { infarction }^{\dagger} \\
(\mathrm{n}=146)\end{array}$ & $\begin{array}{c}\text { Clinical myocardial } \\
\text { infarction }^{\ddagger} \\
(\mathrm{n}=506)\end{array}$ & $\mathrm{p}$ Value \\
\hline Age (years) & $64.5 \pm 10.2^{\S}$ & $67.0 \pm 10.6^{\pi}$ & $64.4 \pm 11.2$ & 0.013 \\
\hline Male & $11,760 / 15,316(76.8 \%)$ & $105 / 146(76.9 \%)$ & $389 / 506(76.2 \%)$ & \\
\hline Female & $3,556 / 15,316(23.2 \%)$ & $41 / 146(23.1 \%)$ & $117 / 506(23.8 \%)$ & \\
\hline Body mass index $\left(\mathrm{kg} / \mathrm{m}^{2}\right)$ & $28.1 \pm 4.5$ & $28.2 \pm 4.6$ & $28.3 \pm 4.2$ & 0.834 \\
\hline Insulin-dependent diabetes mellitus & $1,146 / 15,270(7.5 \%)^{\top}$ & $17 / 146(11.6 \%)$ & $60 / 505(11.9 \%)$ & $<0.001$ \\
\hline Hypertension & $11,241 / 15,263(73.6 \%)$ & $108 / 145(74.5 \%)$ & $366 / 506(72.3 \%)$ & 0.781 \\
\hline Hypercholesterolemia & $10,322 / 14,835(69.6 \%)$ & $91 / 141(64.5 \%)$ & $355 / 489(72.4 \%)$ & 0.151 \\
\hline Current smoker & $3,992 / 15,316(26.1 \%)$ & $28 / 146(19.2 \%)^{\pi}$ & $149 / 506(29.4 \%)$ & 0.037 \\
\hline Peripheral vascular disease & $945 / 14,231(6.2 \%)^{\pi}$ & $7 / 144(4.9 \%)$ & $53 / 502(10.6 \%)$ & $<0.001$ \\
\hline Chronic obstructive pulmonary disease & $776 / 14,470(5.1 \%)$ & $8 / 145(5.5 \%)$ & $37 / 505(7.3 \%)$ & 0.081 \\
\hline Previous coronary artery bypass grafting & $862 / 14,441(5.6 \%)^{\S, \Upsilon}$ & $17 / 146(11.6 \%)$ & $64 / 506(12.6 \%)$ & $<0.001$ \\
\hline Clinical presentation & & & & 0.017 \\
\hline Stable angina & $8154 / 15316(53.2 \%)^{\pi}$ & $86 / 146(58.9 \%)^{\pi}$ & $241 / 506(47.6 \%)$ & \\
\hline Acute coronary syndrome & $7162 / 15316(46.8 \%)^{\natural}$ & $60 / 146(41.1 \%)^{\top}$ & $265 / 506(52.4 \%)$ & \\
\hline
\end{tabular}

Data are shown as mean \pm standard deviation or number of patients $(\%)$.

* Defined as an estimated glomerular filtration rate of creatinine clearance of $<60 \mathrm{ml} / \mathrm{min}$ per $1.73 \mathrm{~m}^{2}$ based on the Modification of Diet in Renal Disease formula.

${ }^{\dagger}$ Equal to BIMR-identified nonclinically correlated Q-wave MI.

${ }^{\ddagger}$ Patients had either site-reported MI or BIMR-identified clinically correlated new QWMI or both. Patients $(\mathrm{n}=8)$ who had concomitant site-reported MI and BIMR-identified nonclinically correlated MI were not included. ANOVA test was used to compare continuous variables.

${ }^{\S} \mathrm{p}<0.05$ (compare to silent MI group).

$\uparrow^{\mathrm{p}}<0.05$ (compare to clinical MI group).

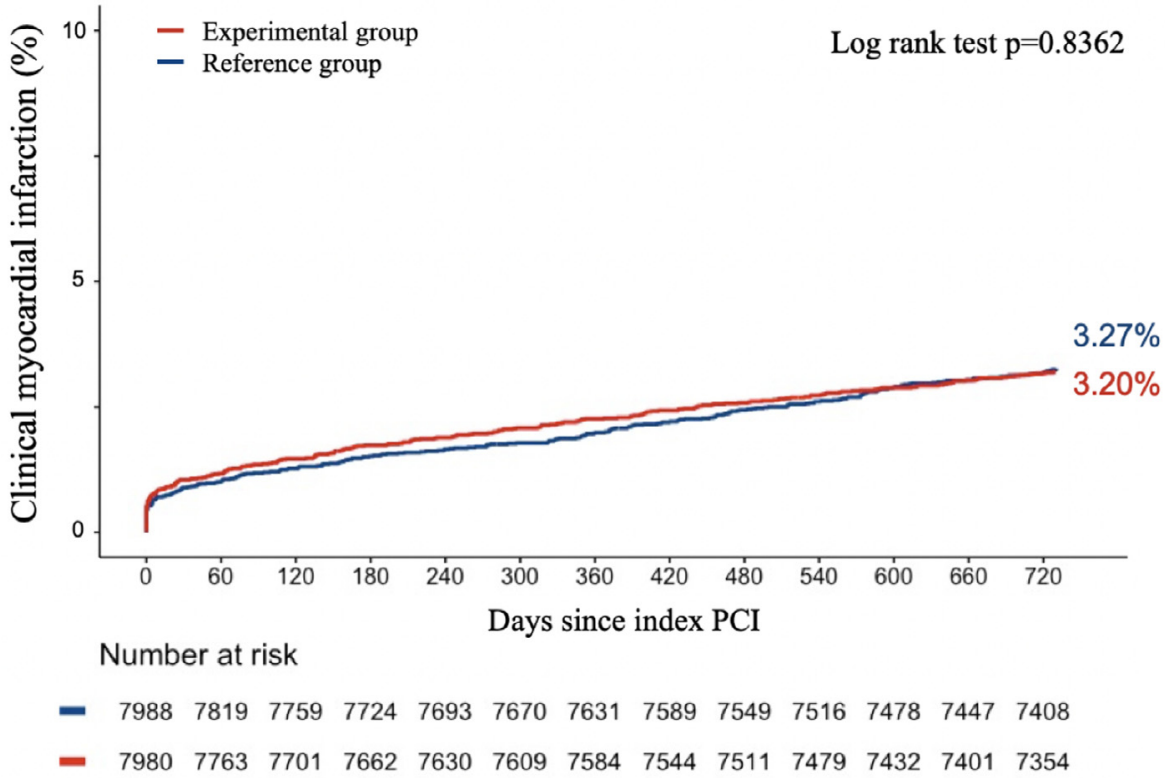

Figure 3. Kaplan-Meier curve for clinical myocardial infarction at 2 years. 

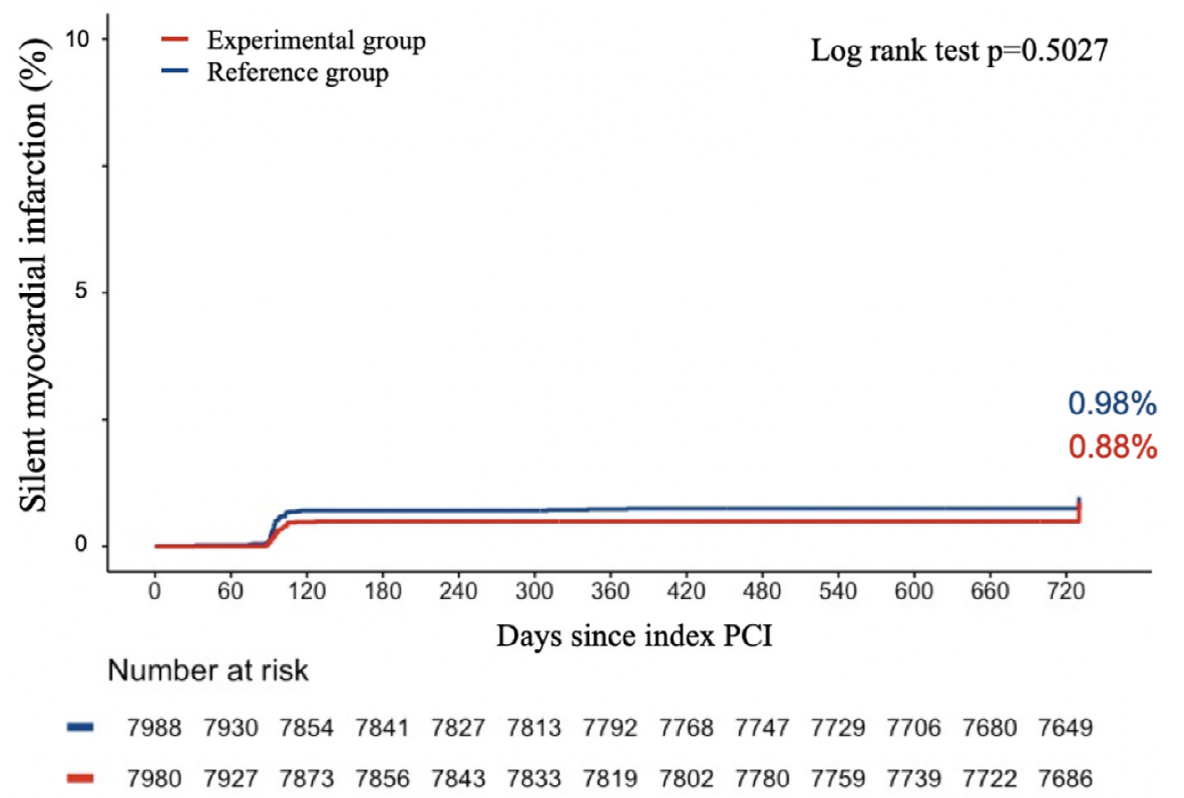

Figure 4. Kaplan-Meier curve for silent myocardial infarction at 2 years.

follow-up of 8.9 years. Moreover, silent MI was associated with an increased risk of heart failure, cardiovascular death, and all-cause death. ${ }^{6,7}$ In the abovementioned 2 studies, silent MI was defined based on the ECG findings with the use of the Minnesota code ${ }^{10}$ or the Novacode ${ }^{14,15}$ which are the 2 most widely used ECG coding system providing predictive values for cardiovascular outcomes. ${ }^{16}$

The ECG remains a cornerstone in the management of cardiovascular disease and is a simple and inexpensive tool to ascertain silent MI in epidemiological and clinical trials. A clinical pathway for ascertainment of silent MI is yet to be established with respect to the timing of ECG surveillance, analysis methodology, and appropriate adjudication of this end point. Some uncertainties encountered with the assessment of new QWMI in our study are worthy of emphasis.

There is no consensus on how frequently to monitor ECG to detect QWMI in asymptomatic patients or whether surveillance for QWMI should be routinely implemented for clinical trials. According to the 2017 Cardiovascular and Stroke Endpoint Definitions for Clinical Trials, it states that "It may be reasonable to perform annual ECGs in clinical trials to monitor for silent MI events if the study population is expected to have an accelerated rate of atherosclerotic events." ${ }^{2}$ Both the 2017 consensus report ${ }^{2}$ and the Universal Definition of Myocardial Infarction ${ }^{1}$ emphasize the importance of obtaining a repeat ECG to assess potential lead misplacement, interviewing the patient to assess for unreported episodes of chest pain (or equivalent-indigestion) and review of additional imaging studies such as echocardiogram or cardiac magnetic resonance if available. Although recognizing abnormality on other imaging studies is not a prerequisite for a silent QWMI, it might be useful to confirm the diagnosis, especially when ECG is equivocal. Moreover, there are some nonischemic causes for new Q waves and confounds the diagnosis of silent MI.
Cardiomyopathy, cardiac amyloidosis, conduction disturbances, myocarditis, acute cor pulmonale, hyperkaliemia, etc, may be associated with Q waves or QS complexes in the absence of MI. ${ }^{17}$ Strictly following the epidemiological ECG coding is not an appropriate approach to ascertain silent MI. Therefore, as there was a BIMR process to adjudicate clinically relevant MI in the GLOBAL LEADERS it is consistent with that philosophy.

Traditionally, Q-waves on the ECG were considered as an irreversible marker of transmural scar. The sensitivity of Q-waves for diagnosis of myocardial scars identified by positron emission tomography differs in different locations (anterior 53\%, inferior 62\%, lateral $25 \%$, and septal $67 \%){ }^{18}$ Q-wave regression or disappearance has been observed in patients with a clinically-evident QWMI. ${ }^{19,20}$ The disappearance of Q-wave after clinically-evident MI may represent the recovery of coronary perfusion and myocardial viability. ${ }^{21,22}$ Wasserman et al reported that disappearance of previously documented diagnostic Q-waves occurred in $14.2 \%$ of 4,254 patients who had a previous MI event. ${ }^{20}$ Recently, Delewi et al showed that $40 \%$ of patients with ST elevation MI treated by primary PCI displayed Qwave regression at 24 months of follow-up. Furthermore, patients with Q-wave regression had significantly larger improvement of left ventricular systolic function compared with those with persistent Q-waves on ECG. ${ }^{23}$ In the GLOBAL LEADERS trial, the disappearance of Q-waves was observed in $28.5 \%$ (53 of 186) of patients with new QWMI during the 2-year follow-up. Adjudication of disappearing Q-waves has not been standardized, although this entity is well recognized. ${ }^{2}$ The evidence suggests that a detected silent QWMI that later disappears represents a true event, thus, seems reasonable to adjudicate silent QWMIs irrespective of changes at follow-up. In the GLOBAL LEADERS trial the protocol defined a new QWMI when a new major $\mathrm{Q}$ wave abnormality presented on the ECG. The 
Steering Committee decided to include all new QWMI regardless of the disappearance or persistence of Q-waves during follow-up. The clinical relevance of Q-wave disappearance in patients with silent MI warrants further investigation.

With respect to the correlation between site-reported new QWMI and core lab-identified new QWMI, there were only $24.3 \%$ of site-reported new QWMI confirmed as nonfatal new QWMI by the BIMR and the core lab. This discrepancy might be attributed to different definition of new Q-waves or we may overlook some true site-reported new QWMI when Q-waves regressed and there was no event ECG to confirm they had ever been there. In addition, sitereported new QWMI followed by a death event within 28 days were also disregarded since these were defined as fatal events.

There are some limitations to be acknowledged in our study. First of all, the ECG information was incomplete in $7.1 \%$ of patients (ECG not received $5.7 \%$ and unanalyzable 1.4\%). The prevalence of new QWMI and silent MI might be slightly underestimated in this context. Secondly, policy of a confirmatory ECG to exclude subtle lead misplacement and lack of other imaging studies to confirm the diagnosis of silent MI had to be acknowledged. Lastly, limited resource of this investigator-initiated study precluded formal event adjudication and monitoring in 15,991 study participants.

In conclusion, in this large-scale randomized trial, we showed that silent MI comprised 1/5 of all MI in an allcomers population with coronary artery disease undergoing PCI. One third of new Q-waves disappeared over time in our study. Given the frequency of silent MI and the need for precise predefined rules for its ascertainment, the validity of silent MI as part of a composite end point requires further scrutiny.

\section{Disclosures}

Dr. Chang received grants from Taipei Veterans General Hospital-National Yang-Ming University Excellent Physician Scientists Cultivation Program (No.107-V-A-002).

Dr. Spitzer received institutional grants from European Cardiovascular Research Institute, during the conduct of the study.

Dr. Gori received speakeŕs fees from Abbott Vascular.

Dr. Zaman received lecture and consulting fees from sanofi, astra, daiichi-sankyo.

Dr. Steg received grants and personal fees from Bayer/ Janssen, grants and personal fees from Merck, grants and personal fees from Sanofi, grants and personal fees from Amarin, personal fees from Amgen, personal fees from Bristol Myers Squibb, personal fees from Boehringer-Ingelheim, personal fees from Pfizer, personal fees from Novartis, personal fees from Regeneron, personal fees from Lilly, personal fees from AstraZeneca, grants, personal fees and non-financial support from Servier, outside the submitted work.

Dr. Jüni received grants from Canadian Institutes of Health Research (CIHR), during the conduct of the study; grants from Astra Zeneca, grants from Biotronik, grants from Biosensors International, grants from Eli Lilly, grants from The Medicines Company, outside the submitted work; and Peter Jüni serves as unpaid member of the steering group of trials funded by Astra Zeneca, Biotronik, Biosensors, St. Jude Medical and The Medicines Company.

Dr. Hamm received personal fees from AstraZeneca, outside the submitted work.

Dr. Vranckx received personal fees from Astra Zeneca, personal fees from Bayer Health Care, personal fees from Daiichi Sankio, personal fees from Terumo, personal fees from CLS Behring, outside the submitted work.

Dr. Valgimigli received grants and personal fees from Abbott, personal fees from Chiesi, personal fees from Bayer, personal fees from Daiichi Sankyo, personal fees from Amgen, grants and personal fees from Terumo, grants from Medicure, personal fees from Alvimedica, grants and personal fees from Astrazeneca, personal fees from Biosensors, outside the submitted work.

Dr. Windecker received research and educational grants from Abbott, Amgen, Bayer, BMS, Boston Scientific, Biotronik, CSL Behring, Edwards Lifescience, Medtronic, Polares and Sinomed.

Dr. Serruys received personal fees from Cardialysis, personal fees from Medtronic, personal fees from Sino Medical Sciences Technology, personal fees from Société Europa Digital Publishing, personal fees from Stentys France, personal fees from Philips/Volcano, personal fees from St. Jude Medical, outside the submitted work.

Dr. Onuma reports being a member of advisory board of Abbott vascular.

\section{Acknowledgment}

The authors would like to acknowledge the major contribution of Eugene McFadden to this scientific document and specifically acknowledge for his intellectual input in manuscript editing.

\section{Supplementary materials}

Supplementary material associated with this article can be found in the online version at https://doi.org/10.1016/j. amjcard.2019.08.049.

1. Kannel WB, Abbott RD. Incidence and prognosis of unrecognized myocardial infarction. An update on the Framingham study. $N$ Engl J Med 1984;311:1144-1147.

2. Hicks KA, Mahaffey KW, Mehran R, Nissen SE, Wiviott SD, Dunn B, Solomon SD, Marler JR, Teerlink JR, Farb A, Morrow DA, Targum SL, Sila CA, Hai MTT, Jaff MR, Joffe HV, Cutlip DE, Desai AS, Lewis EF, Gibson CM, Landray MJ, Lincoff AM, White CJ, Brooks SS, Rosenfield K, Domanski MJ, Lansky AJ, McMurray JJV, Tcheng JE, Steinhubl SR, Burton P, Mauri L, O'Connor CM, Pfeffer MA, Hung HMJ, Stockbridge NL, Chaitman BR, Temple RJ, Standardized Data Collection for Cardiovascular Trials I. 2017 Cardiovascular and stroke endpoint definitions for clinical trials. Circulation 2018;137: 961-972.

3. Sheifer SE, Manolio TA, Gersh BJ. Unrecognized myocardial infarction. Ann Intern Med 2001;135:801-811

4. Pride YB, Piccirillo BJ, Gibson CM. Prevalence, consequences, and implications for clinical trials of unrecognized myocardial infarction. Am J Cardiol 2013;111:914-918.

5. Burgess DC, Hunt D, Li L, Zannino D, Williamson E, Davis TM, Laakso M, Kesaniemi YA, Zhang J, Sy RW, Lehto S, Mann S, Keech AC. Incidence and predictors of silent myocardial infarction in type 2 
diabetes and the effect of fenofibrate: an analysis from the Fenofibrate Intervention and Event Lowering in Diabetes (FIELD) study. Eur Heart J 2010;31:92-99.

6. Zhang ZM, Rautaharju PM, Prineas RJ, Rodriguez CJ, Loehr L, Rosamond WD, Kitzman D, Couper D, Soliman EZ. Race and sex differences in the incidence and prognostic significance of silent myocardial infarction in the Atherosclerosis Risk in Communities (ARIC) Study. Circulation 2016;133:2141-2148.

7. Qureshi WT, Zhang ZM, Chang PP, Rosamond WD, Kitzman DW, Wagenknecht LE, Soliman EZ. Silent myocardial infarction and longterm risk of heart failure: The ARIC Study. J Am Coll Cardiol 2018;71:1-8

8. Vranckx P, Valgimigli M, Windecker S, Steg PG, Hamm C, Juni P, Garcia-Garcia HM, van Es GA, Serruys PW. Long-term ticagrelor monotherapy versus standard dual antiplatelet therapy followed by aspirin monotherapy in patients undergoing biolimus-eluting stent implantation: rationale and design of the GLOBAL LEADERS trial. EuroIntervention 2016:12:1239-1245.

9. Vranckx P, Valgimigli M, Juni P, Hamm C, Steg PG, Heg D, van Es GA, McFadden EP, Onuma Y, van Meijeren C, Chichareon P, Benit E, Mollmann H, Janssens L, Ferrario M, Moschovitis A, Zurakowski A, Dominici M, Van Geuns RJ, Huber K, Slagboom T, Serruys PW, Windecker S, Investigators GL. Ticagrelor plus aspirin for 1 month, followed by ticagrelor monotherapy for 23 months vs aspirin plus clopidogrel or ticagrelor for 12 months, followed by aspirin monotherapy for 12 months after implantation of a drug-eluting stent: a multicentre, open-label, randomised superiority trial. Lancet 2018;392:940-949.

10. Prineas RJ CR, Zhang Z-M. The Minnesota Code Manual of Electrocardiographic Findings. London: Springer Science \& Business Media; 2009.

11. Thygesen K, Alpert JS, Jaffe AS, Simoons ML, Chaitman BR, White HD, Joint ESCAAHAWHFTFftUDoMI, Katus HA, Lindahl B, Morrow DA, Clemmensen PM, Johanson P, Hod H, Underwood R, Bax JJ, Bonow RO, Pinto F, Gibbons RJ, Fox KA, Atar D, Newby LK, Galvani M, Hamm CW, Uretsky BF, Steg PG, Wijns W, Bassand JP, Menasche P, Ravkilde J, Ohman EM, Antman EM, Wallentin LC, Armstrong PW, Simoons ML, Januzzi JL, Nieminen MS, Gheorghiade M, Filippatos G, Luepker RV, Fortmann SP, Rosamond WD, Levy D, Wood D, Smith SC, Hu D, Lopez-Sendon JL, Robertson RM, Weaver D, Tendera M, Bove AA, Parkhomenko AN, Vasilieva EJ, Mendis S. Third universal definition of myocardial infarction. Circulation 2012;126:2020-2035.

12. Group BDS, Frye RL, August P, Brooks MM, Hardison RM, Kelsey SF, MacGregor JM, Orchard TJ, Chaitman BR, Genuth SM, Goldberg SH, Hlatky MA, Jones TL, Molitch ME, Nesto RW, Sako EY, Sobel BE. A randomized trial of therapies for type 2 diabetes and coronary artery disease. $N$ Engl J Med 2009;360:2503-2515.
13. Chaitman BR, Hardison RM, Adler D, Gebhart S, Grogan M, Ocampo S, Sopko G, Ramires JA, Schneider D, Frye RL, Bypass Angioplasty Revascularization Investigation 2 Diabetes Study G. The Bypass Angioplasty Revascularization Investigation 2 diabetes randomized trial of different treatment strategies in type 2 diabetes mellitus with stable ischemic heart disease: impact of treatment strategy on cardiac mortality and myocardial infarction. Circulation 2009;120:2529-2540.

14. Chaitman BR, Zhou SH, Tamesis B, Rosen A, Terry AB, Zumbehl KM, Stocke K, Takase B, Gussak I, Rautaharju PM. Methodology of serial ECG classification using an adaptation of the NOVACODE for Q wave myocardial infarction in the Bypass Angioplasty Revascularization Investigation (BARI). J Electrocardiol 1996;29:265-277.

15. Rautaharju PM, Park LP, Chaitman BR, Rautaharju F, Zhang ZM. The Novacode criteria for classification of ECG abnormalities and their clinically significant progression and regression. J Electrocardiol 1998:31:157-187.

16. Zhang ZM, Prineas RJ, Eaton CB. Evaluation and comparison of the Minnesota Code and Novacode for electrocardiographic Q-ST wave abnormalities for the independent prediction of incident coronary heart disease and total mortality (from the Women's Health Initiative). Am J Cardiol 2010;106:18-25.e12.

17. Thygesen K, Alpert JS, Jaffe AS, Chaitman BR, Bax JJ, Morrow DA, White HD, Group ESCSD. Fourth universal definition of myocardial infarction (2018). Eur Heart J 2019;40:237-269.

18. Yang H, Pu M, Rodriguez D, Underwood D, Griffin BP, Kalahasti V, Thomas JD, Brunken RC. Ischemic and viable myocardium in patients with non-Q-wave or Q-wave myocardial infarction and left ventricular dysfunction: a clinical study using positron emission tomography, echocardiography, and electrocardiography. J Am Coll Cardiol 2004;43: $592-598$.

19. Karnegis JN, Matts J, Tuna N. Development and evolution of electrocardiographic Minnesota Q-QS codes in patients with acute myocardial infarction. Am Heart J 1985;110:452-459.

20. Wasserman AG, Bren GB, Ross AM, Richardson DW, Hutchinson RG, Rios JC. Prognostic implications of diagnostic Q waves after myocardial infarction. Circulation 1982;65:1451-1455.

21. Barold SS, Falkoff MD, Ong LS, Heinle RA. Significance of transient electrocardiographic Q waves in coronary artery disease. Cardiol Clin 1987:5:367-380.

22. Nagase K, Tamura A, Mikuriya Y, Nasu M. Significance of Q-wave regression after anterior wall acute myocardial infarction. Eur Heart J 1998;19:742-746.

23. Delewi R, Ijff G, van de Hoef TP, Hirsch A, Robbers LF, Nijveldt R, van der Laan AM, van der Vleuten PA, Lucas C, Tijssen JG, van Rossum AC, Zijlstra F, Piek JJ. Pathological Q waves in myocardial infarction in patients treated by primary PCI. JACC Cardiovasc Imaging 2013;6:324-331. 